was that of an Australian gentleman, on whom I performed Wheelhouse's operation in January, 1890 , but of whom I lost sight almost directly, as be returned to Australia. He had instructions to pass a large bougie once every six weeks or two months. I saw him in November last, and passed a No. 12 bougie without meeting with any trace of the stricture. He then informed me that he had lost his bougies on the voyage out to Australia, and that " he had been too busy to see about getting any more"; and that, consequently, no instrument had been passed for more than eighteea months. The second case was that of a man on whom I performed Touley's operation for stricture in June last, at King's College Hospital. No catheter was left in ; it was merely passed every six hours for the first five days, and affer that the man micturated normally. No wrine came through the perineal wound, which healed by first intention, and the patient left the hospital on the fourteenth day. A bougie was passed once a week for the first three weeks; then once, a month later; then again after an interval of two months; and finally four months later still. $\mathrm{He}$ is to have the next one passed in eight months' time. A No. 12 detects no trace of stricture. The possibility of a permanent cure of stricture after operation quite accords with what we find on examining the site of such operations after deatb. The incision in the strictured urethral wall is occupied by a very delicate film of cicatricial tissue which presents a marked contrast to the dense tissue of the stricture itself. It can well be understood how such a thin web can be kept permanently dilated by the urine stream. And it follows, too, from this that the reason why old dense strictures, where there is foul urine \&c., relapse more rapidly after urethrotomy than do those where such changes have not taken place, is that the septic condition of the perineal wound favours the production of new connective tissue, and so replaces the divided stricture by one of new formation.

Weymouth-street, W.

\section{ENLARGEMENT OF THE SPLEEN IN YOUNG CHILDREN.}

BY J. WALTER CARR, M.D., M.R.C.P., PHYSICIAN TO OUT-PATIENTS, VICTORIA HOSPITAL FOR CHILDREN, CHELSEA.

As in adults so in children, enlargement of the spleen may be due to numernus and well recognised causes, some of an acnte, others of a chronic character. Typhoid fever, malaria, leucocy thæmia, tuberculosis, embolism, lardaceous disease, cirrhosis of the liver, - -each one of these may of course produce a greater or less hypertrophy of the spleen. But whilst in very young children enlargements due to any of the above-mentioned conditions are comparatively rare, and not usually difficult of diagnosis when they do occur, there is a splenic hypertrophy found in infants, very chronic in its course, very serious in its prognosis, so frequent in its occurrence as probably to ou o-number all the cases of enlarged spleen due to other causes during infancy, and yet so ill defined in its etiology that it has hardly acquirr $d$ a distinctive name, and in many medical works is only referred to incidentally under the heading of rickets or of syphilis. Nevertheless, its course, symptoms, and pathological anatomy appesr to be so definite and characteristic as to constitute it a disease suigeneris, and entitle it to as well-defined a place in our classitication as has been assigned to the allied conditions leucocytbæmia and lymph adenoma, from which however, as we shall presently see, it is easily distinguished. Perhaps the term "splenic anæmia," proposed by Griesinger, is the best to assign to it. It is necessary to distinguish a spurious from a real enlargement of the spleen in children; sometimes, withonb any genuine hypertrophy, it is considerably longer and thlnner than natural; under such circumstances, particularly shonld it be pushed down by the contraction of a rachitic thorax, the lower end may be felt below the ribs, but it feels soft, not hard; there are none of the characteristic symptoms associated with genuine hy pertrophy, and several times at a necropsy I have found that, though considerably elongated, the weight of such a spleen has not been abnormal or its consistence increased.

The following description of the symptoms and course of the disease is based on thirty cases observed during the last three years at the Victoria Hospital for Children, Chelsea. During that period not a single example of genuine leucocythrmia came under my observation, and the cases of enlarged spleen from all other causes (chiefly tubercular) in children under three years of age were fewer in number than those of simple splenic anæmia. Sixteen of the patients were males and fourteen females; in age they varied from two months to two years and a half when first seen. They were usually wasted, but by no means invariably so, particularly the slighter and earlier cases; but only in one or two instances were the children really plump and well developed. There was nearly always some pallor; this was extremely marked in the more severe cases, and was associated often with the more especially characteristic splenic appearance-a waxy colour with a faint olive tint, indicating almost at a glance the nature of the case. The degree of enlargement of the spleen varied; in nearly every instance it could be distinctly felt at least an inch or an inch and a half below the costal margin, and in about half the cases it extended down to the level of the anterlor superior iliac spine and forwards nearly to the umbilicus. It alwass felt exceedingly hard, and was not usually tender. It must be remembered that in children the costo-colic fold of peritonenm is much firmer than in adults ; so that in the earlier stages of splenic enlargement it directs the lower end of the organ forwards, and so prevents it from projecting as far below the ribs as it otherwise would, and perhaps causes it to encroach more on the thoracic cavity. The liver was apparently enlarged in about half the cases; but libtle importance can be atoached to the extent of $i$ ibs projection below the costal margin, on account of the varying contraction of the chest by rickets, and the weight of the organ post mortem never indicated any decided hypertrophy. There was usually also swelling of some of the external lymphatic glands, but never to any marked extent; they were always hard and freely movable. In four of the fatal cases $(8,15,16$, and 30$)$ hæmorrhages occurred-either epistaxis or small scattered purpuric spots in the skin, or both,-and Case 6 , the child recently under treatment in Westminster Hospital, had profuse epistaxis shortly before admission there. These bæmorrhages probably depend solely on the severe anæmia, for, as Dr. Siephen Mackenzie pointed out in his Lettsomian Lectures on Anæmia in 1891, they may be met with whenever the proportion of red blood-eorpuscles falls below 50 per cent. of the normal, a condition which obtained in all the cases referred to. In a similar way may be explained iriegular attacks of moderate pyrexia, which occurred from time to time in the more severe cases whilst under observation in the wards. There was seldom an opportunitv of examining the urine, but in two patients (Cases 15 and 30) a faint cloud of albumen was present, and ia three others (Cases 5, 6, and 7) it was noted to be absent. According to Dr. Crozer Griffith, in Keating's Encyclopædia of Diseases of Children (vol iii, page 799), the urine in this disease does not contain albumen. The blood was examined, once or oftener, in fifteen of the children, and showed mereiy a condition of simple anæmia. In the. most severe cases in was distinctly watery and paler than natural, and flowed very freely from a small prick. The red corpuscles always ran into ronleaux ; they varied consider ably in size, but presented no abnormal shape. In number they ranged from 32 to 78 per cent. of the normal ; in only three instances, however, was the percentage less than 40 , and two of these were fatal ; the general range was from 45 to 70 per cent; and even this may give somewhat too low an average, as in several cases in which the blood was not examined the anæmia was not at all profound. In one infant (Case 8) the number of red dises fell in eleven weeks from 64 per cent. to 37 per cent., then under treatment with reduced iron rose again to 63 per cent. when the patient died of diphtheria. In another instance (Case 20) which steadily improved the percentage rose from 62 to $82 \cdot 6$. The percentage of hæmoglobin was ascertained in seven of the cases, and was not found to bear any definite relationghip to the number of red corpuseles; in all, however, as in simple anæmia and chlorosis, and in contrast with pernicions ancemia, it was deficient, both actually and also relatively, to the number of corpuscles. The hæmoglobin value of the individual corpuscle was usually from 50 to 67 per cent., but in one case (19) in which the percentage of red discs was 78 , two estimations of the bæmoglobin gave only 25 . and 28 per cent. respectively. From the few cases in which ceveral estimations were made the increase or decrease of 
hæmoglobin seemed roughly to vary pari passu with that of the red corpuscles. It is perhaps doubtful whether the results of examination of the blood with the hrmoglobinometer are very reliable in childhood, and $I$ shall be glad to hear the opinions of others on this point. In nearly every instance there was a slight excess of white corpuscles, but this was not marked, especially when we remember that in young children they are normally somewhat more numerous relatively than in adults-in infants, 1 white to from 130 to 210 red corpuscles. In only one instance (Case 8 ) did the percentage of white discs approach the leucocy themic condition, and that was after epistaxis, when the red corpuscles fell to 37 per cent, with ' 1 white to 33 red ones. In this case all the lymphatic glands, both internal and external, were enlarged, though none were bigger than a small filbert; even the Peyer's patches and solitary glands of the intestine were found distinctly swollen. In the other cases there was 1 white to from 70 to 225 red discs, averaging about 1 to 100 , so that it is quite evident that this disease is distinct from leucocy thremia.

It is well known that anæmia is often a prominent symptom of rickets, and, as nearly all these children were rickeby, the question naturally arises whether the blood changes described were dependent mainly or even entirely upon the rickets. It seems to me, however, that, at any rate in the marked cases, the anæmia was always more grofound than coald be explained by the rickets alone, and, more particularly, that the diminution of red corpuscles does not occur to such an extent in simple rickets. Thus, in one case of well-marked rickets and anæmia, I found 98 per cent. of red discs and only 28 per cent. of hæmoglobin, and in twins with marked rickets and pallor the percentage of red corpuscles in each was about 80 and of hsemoglobin 70 . As I have already stated, in none of my cases of splenic enlargement did the percentage of red dises exceed 78. Moreover, in the blood of cases of simple rickets there does not seen to be the same tendency to even a slight excess of white corpuscles.

The conrse of the disease is essentially chronic, and so it is difficult in out.patient practice to trace the cases to their termination. In some instances the splenic enlargement and the anæmia steadily increase, bæmorrhages occur, and the child dies at last from exhaustion, usually complicated by more or less catarrh of the mucous membranes, leading to bronchitis and broncho-pneumonia, or to diarrhoe. Ten of my thirty cases are known to have died mainly in the way just mentioned; but this is, perhaps, a higher mortality than that of a number of cases taken indiscriminately, as the thirty cases include an undue proportion treated as inpabierts on account of their specially severe symptoms. Six of the cases could not be traced, of the remainder thirteen were found either to bave completely recovered or to be steadily improving; Case 6 alone remained in statu quo. In Case 3, after only four months of treatment, the child's general condition and colour were greatly improved and the spleen could scarcely be felt, but this was a slight case from the first, and the spleen was never much enlarged. In Case 10, examined after a year and eight months, the spleen could not be felt, and the red discs had risen from 42 per cent. to 104 per cent. In Case 19, after eight months, although the spleen was still enlarged, the red corpuscles had risen from 78 per cent. to 98 per cent., and the hremoglobin from 26 per cent. to 45 per cent. In Case 20 the spleen at first reached to the level of the anterior su perior iliac spine, and the anterior border was in the nipple lise; the lower border of the liver was felt half way $\mathrm{b} r$, ween the umbilicus and the ribs; the inguinal glands we enlarged. Five months later the child was stouter and of better colour, the spleen could not be felt, the liver only projected an inch below the costal margin, and there was no glandular enlargement. From the first, however, the anæmia in this case was not extreme-viz., red discs 62 per cent., hæmoglobin 45 per cent.; the former rose to 825 per cento, the latter remaining about the same. In Case 22 the spleen was nearly as large as in the one juat described; after three months it only reached an inch below the ribs, and there was much improvement in the child's colour and nutrition; it unfortunately succumbed to an attack of whooping-cough. Occasionally there seevos to be no definite change after several months of treatment; Case 6 shows this especially, as after two years the child's condition was almost unaltered, the anæmia much the same, and the spleen a little larger.
The prognosis of cases of splenic anæemia as given by different writers varies immensely. Crozer Griffith, in Keating's Eacyclopædia, says that permanent cures are of the rarest occurrence unless the splenic enlargement bo due to syphilis or malaria; Henoch says that most of the children die from progressing anæmia, wasting, and, finally, dropsy of the cavities; Eustace Smith, on the other hasd, gives a much more favourable prognosis; whilst Ashby and Wright state that most of the cases improve after a while, but that their course is very chronic. From my own observations I should say that the prognosis in these cases is not necessarily bad, though the disease will probably be of long duration; bat should the spleen get very large and the anæmia profound, there is of course great danger of death from simple asthenia, from pulmonary trouble, or from the onset of any acute specific disease, which will probably prove rapidly fatal in a child already greatly weakened. Although the pro. gnosis is usually more unfavourable the greater the enlargement of the spleen, yet it is interesting to note that in Case 4 , in which the child steadily got worse and had marked anæmia, the organ was only slightly enlarged, weighing one ounce. Later on I shall mention facts which seem to point to the presence of well-marked syphilitic manifestations being a particularly unfavourable indication.

Morbid anatomy.-A necropsy was obtained in seven (Cases $4,8,15,16,26,27$, and 30 ) of the ten fatal cases. In all there were great emaciation and pallor of the internal organs, in four marked bronchitis or broncho-pneumonia. Case 4 was the only one in which there was any sign of bubercle, in this case there was a mass of caseous mesenteric glands. The liver was but slightly, if at all, enlarged in any in. stance, its greatest weight being fifteen ounces and a balf. In appearance it was either normal or paler than natural ; in only two of the cases (4 and 26) was it notably tougher than usual, and in two others ( 8 and 15 ) the consistence was very slightly increased. In one case (8) there was a depressed scar-like patch in the liver, perhaps the remains of a gumnsa; this was the only indication of visceral syphilis lound in any examination. We may conclude, then, that the changes which the liver undergoes in these cases are unimportant, and that its enlargement is apparent rather than real, being due either to the relatively larger size of the liver in infancy or to the contraction of a rachivic thorax.

As regards the internal lymphatic glands, in no case was there any swelling of those in the thorax beyond what would be attributable to bronchitis or broncho-pneumonia. In four cases the mesenteric glands were normal; in one case, as already mentioned, caseous; and in two (Cases 8 and 16) slightly swollen. The bone marrow I have not examined, but it is said that that of the long bones may present in some cases the same dark-red lymphoid appearance frequently seen in pernicious anæmia. ${ }^{1}$ In two cases the spleen was slightly adherent to the surrounding parts, and in a third there were a few flakes of lymph on the surface, but in no instance was there any distinct thickening of the capsule. In one case (4) the organ was but slightly enlarged, weighing $1 \mathrm{oz}$; in the others it varied from $40 \mathrm{z}$ to $8 \frac{1}{2} \mathrm{oz}$. in weight. In all it was firm, and the consistence was distinctly increased ; the section was dark and fleshy, but otherwise fairly natural in appearance, with no enlargement of the Malpighian corpuseles. Iodine solution gave no albuminoid reaction. None of the other organs presented any noteworthy change. The microscope confirmed the naked.eye appearance of the spleen by showing that the enlargement was apparently due to a simple hypertrophy, with more or less increase of fibrous tissue. In one case (8) there were scattered patches having somewhat the aspect of albuminoid change, a condition probably identical with the hyaline fibrosis which Cheadle has described. ${ }^{2}$ The microscope showed no important changes in the liver or lymphatic glands, but in some instances there seemed to be slight overgrowth of connective tissue in the kidneys. The appearances presented by the spleen seemed to be the same whether the enlargement were associated with syphilis, with rickets, or with neither of these diseases; it also resembles the ague spleen. The condition described corresponds with the descriptions given by other writers, especially by Henoch and by Ashby and Wright; but I carnot be sure whether Jenner refers to a similar condition, when in his lectures on Rickets he speaks of an albuminoid infiltration of the spleen, with some simi-

Dr. Crozer Griffth's article on "Splenic Anæmia," in Keating's Encyclopadia of Diseases of Children.

Brit. Med. Jour., ii. 1888, p. 1148 
Far affection of the liver and lymphatic glands, leading to enlargement of all these organs, and causing the emaciation seen in some cases of rickets. He describes the spleen as non-adherent, capsule scarcely if at all thickened, the substance of the organ tough but elastic, pale-red or dark-purple in colour; liver usually only slightly enlarged, heavy, tough, and semi-transparent; external lymphatic glands enlarged, not tender, and never inflamed. Although he speaks of an albuminoid infiltration of all these organs, he says that it has not the characters of the albuminoid change described by Virchow, and especially that it does not give any reaction with iodine solution. On the whole, from the general symptoms and arcompanying conditions of these cases, it seerris probable that the so-called aibuminoid infiltration of the spleen associated by Jenner with certain cases of rickets is identical with the condition which I have been describing.

(Ro be concluded.)

\section{A NOTE ON REID'S UTERINE DILATORS.}

BY JAMES BRAITHWAITE, M.D. LOND.

OBSTETRIC PHYSICIAN TO THE LEEDS GENERAL INFIRMARY.

IN 1888 Dr. Reid of Glasgow brought under the notice of the profession his uterine dilators. These consist of five sonical dilators about two inches in length, which fit on a handle or stem common to all. The smallest of these dilators is a quarter of an inch in diameter at its narrow and, and three eighths of an inch at its widest or proximal end. The largest is one inch in diameter at its widest part. The principle of action is that of a screw wedge. All the dilators have on the surface a shallow blunt screw, so made as not to cut the mucous membrane of the cervical canal of the uterus when introduced by a rotatory movement, but at the same time sufficientiy deep to retain a hold on the parts through which they pass. When the British Medical Association met in Glasgow in $1888 \mathrm{I}$ saw these dilators and procured a set from the makers, Messrs. Filiard and Sons of Glasgow. They have served me in such good stead since in cases in which nothing else would have done that I propose to give two or three examples of their utility, especially as I have never since seen them mentioned in any way in the current medical literature of the day, and their value seems to be not known or appreciated.

In April, 1890, I saw with Dr. Thompson of Great Ouseburn a lady who was in such a condition from pregnancy vomiting that it was necessary to empty the uterus of a two months' fotus in order to save her life if possible. The cervix was extremely rigid. I dilated first by Hegar's dilators, but could only get to size 9 . By no justifiable force could any larger siz $\vec{s}$ be got in ; so $I$ then inserted a large laminaria tent, not having Reid's dilators with me. Next day I again tried with Hegar's; but I only got in two sizes larger. I now used Reid's, which I had meanwhile procured, and dilated ats once to the fourth size; so that the left index finger passed through the cervix, and I completely amptied the uterus of a quantity of semi-putrid secundines by means of Gervis's ovum forceps, but no foetus was found. The patient rallied for a day or so, but soon sank, the vomiting continuing. For three weeks previously the stomach had retained no food whatever, so this result was almost to be expected. The point, however, in the case is the ease with which Reid's dilators acted after the failure of Hegar's.

In October last I had a similar case, but more urgent still, and without these instruments I believe a successful termination of the case would have been impossible. A gentleman married a lady in California. Within a short time she became pregnant, and incessant vomiting necessitated the induction of abortion. She recovered from this, and became pregnant for the second time, but there was no vomiting, and she was delivered of a healbhy male child at full term. She was attended by Drs. Ellerton and Clayton of Aberford, near Lseds, for she came to England to her husband's home. Becoming pregnant for the third time, vomiting came on at once; and when I saw her with her medical attendants named, she appeared to be within two days of her death, the stomach having retained no food for fourteen days. There was no time to wait for anything; the uterus had to be emptied at once. The cervix was closed firmly and felt somewhat hard. I dilated it to the fourth size of Reid's dilator. This took about an hour, as plenty of time should be given in the use of such a powerful instrument. The uterus was then emptied by means of Gervis's ovum forceps. This was upon a Wednesday; the vomiting abated considerably on the Thursday and ceased on the Friday, and the patient then recovered. I had a letter a week afterwards giving these particulars. I believe that no other dilator could have accomplished this, for great power was required; and the upward pressure necessary to introduce Hegar's instruments, one after the other, would have caused the vulsellum with which the uterus must be held to tear out. We have used this instrument extensively in the infirmary wards in the treatment of dysmenorrhœe. I will give one case of dysmenorrhœe, a private one, however, in illustration of its use in this disease.

A lady, thirty-four years of age, and unmarried, had suffered from dysmenorrhœa since she was eighteen, apparently induced by over-exertion in walking. It has become much more severe the last few years, and she had derived no benefit from the treatment of the physician who usually attended the family. In February, 1890, I dilated the cervix with Hegar's dilabors to size 6 or 7 , and inserted a large laminaria tent for the night. On withdrawing this next morning I did nothing further, as the parts were fairly but moderately dilated, and she had taken the ether necessary so badly that I did not like to give it again. No benefit whatever followed this dilatation except for the first time following. In May, 1891, I again dilated and used the tent as before; but on the second morning dilated with Reid's dilator to size 4, not passing it quite up to the full length. This has so far proved an absolute cure. I saw her a few days ago, and she has been as nearly as possible free from pain and is in good health, whereas she was previously almost a chronic invalid.

I could give many obher illustrations, but those given show, I think, the great value of Reid's dilators. In use they simply require oiling and then passing into the cervical canal. The small end of the wedge is quice rounded and smooth. The handle is then rotated and the wedge screws itself in, dilating very gradually, but with immense power. I have never used the largest size, as the fourth one allows of the index finger passing, and I believe the largest size too large for an unimpregnated uterus, and possibly involving risk of laceration. It is necessary to steady the cervix by a vulsellum, or hook, but there is no risk of this tearing out or lacerating the tissues, as I have several times seen when Hegar's are used, for there is no upward dragging. Since this paper was written I have had a patient almost dying from hæmorrhage from what was supposed to be a slonghing fibroid. The cervix was contracted and did not admit the finger, and was woody and hard. It was dilated to the largest size with Reid's dilator, and as much as could be reached of the tumour removed. I thought at the time that it was all removed. The patient died within twenty-four hours from, as the necropsy showed, a large abscess full of offensive pus, but the cervical mucous membrane showed no trace of the action of the screw dilator, and it was examined very carefully in a good light.

I hope these cases may lead to a more general use and appreciation of the instrument, for which the thanks of the profession are due to Dr. Reid.

Leeds.

\section{RELATION OF INFLUENZA TO CLIMATIC CONDITIONS AND TO ZYMOTIC AND RESPIRATORY DISEASES.}

\section{BY C. ROBERTS, F.R.C.S. ENG.}

THE borough of Nottingham has issued an admirable coloured chart and a series of meteorological tables illustrating the relation of the number of deaths from various causes to the principal meteorological conditions on each day of the year 1891, but without any comments. As there was an epidemic of influenza during the ten weeks from April 22nd to June 30th, the chart affords an opportunity of studying the relation of this disease to climatic conditions and the prevalence of other diseases, independently of all 